Check for updates

Cite this: RSC Adv., 2017, 7, 47624

\title{
Shear behavior at high pressures and viscoelastic properties in water and in brine solutions with high salinities for a tetra-polymer containing poly(ethylene oxide) side chains
}

\begin{abstract}
Jingjing Huang, (iD ${ }^{\text {ab }}$ Chuanrong Zhong (D) *ab and Xiaogang $\mathrm{Wu}^{\mathrm{ab}}$
A novel tetra-polymer (PASV) was synthesized using acrylamide(AM), vinyl biphenyl (VP), sodium 2-acrylamido-2-methylpropane sulphonate (NaAMPS), and a novel salt-tolerant macromonomer, allyl-capped octylphenoxy poly(ethylene oxide) with the polymerization degree of $4(\mathrm{AE})$. Consecutive shear behaviors of PASV were investigated at high pressures of 5-20 MPa as well as atmospheric pressure to reveal rheological performance of oil-flooding polymers in oil reservoirs. PASV displays an excellent thickening effect induced by salt as well as good associated behavior in aqueous solutions. Its critical association concentrations are merely $0.7 \mathrm{~g} \mathrm{~L}^{-1}$ and $0.6 \mathrm{~g} \mathrm{~L}^{-1}$ in aqueous solution and in $70 \mathrm{~g} \mathrm{~L}^{-1}$ $\mathrm{NaCl}$, respectively. PASV in $70 \mathrm{~g} \mathrm{~L}^{-1} \mathrm{NaCl}$ exhibits not only obvious shear thickening behavior but also unreported pressure-thickening behavior in an investigated pressure range of atmospheric pressure to $20 \mathrm{MPa}$ at $65^{\circ} \mathrm{C}$. PASV also displays predominantly unexpected elastic behavior both in water and in brine solutions with high $\mathrm{NaCl}$ concentrations.
\end{abstract}

Received 2nd September 2017 Accepted 28th September 2017

DOI: 10.1039/c7ra09771a

rsc.li/rsc-advances these associated polymers are lower than $1.0 \times 10^{7} \mathrm{~g} \mathrm{~mol}^{-1}$. When their polymer concentrations are higher than a critical association concentration $\left(C_{\mathrm{p}}^{*}\right)$, they display a good thickening effect in unsalted solution, salt-thickening, and heatthickening. However, for these polymers, polymer chains are linear and are greatly coiled by the addition of salt because of the electrostatic shielding, and so apparent viscosities of their all brine solutions are much lower than those of unsalted solutions. Moreover, these associated polymers are precipitated from brine solutions at salinities being higher than $70 \mathrm{~g} \mathrm{~L}^{-1}$, and $C_{\mathrm{p}}^{*}$ are on the high side.

Polymer chains are sheared consecutively and shear rates are changed while flowing through pore throats or pores in oil reservoirs. So, shear behaviors of polymer solutions were studied at atmospheric pressure. ${ }^{18}$ In fact, injected pressures of polymer solutions are generally 5-20 MPa in EOR for oil reservoirs, ${ }^{19,20}$ but shear behaviors of oil-flooding polymer solutions at high pressures are not reported in the literature. In addition, when polymer chains migrate in strata, they are expanded or coiled. So, the polymer solutions exhibit viscoelastic behavior in the porous medium. Good viscoelastic properties of polymers can increase microscopic oil-displacement efficiency; residual oil in "dead ends" is pulled out by the viscoelastic polymer solutions, and the thickness of the residual oil film reduces with an increase in elasticity of polymer solutions. ${ }^{21-23}$ Most oilflooding polymers can present good viscoelastic properties in aqueous solutions; however, their elastic characters are lost remarkably with the addition of salt, especially at high
${ }^{a}$ State Key Laboratory of Oil and Gas Reservoir Geology and Exploitation, Chengdu University of Technology, Chengdu 610059, Sichuan, China. E-mail: zhchrong2006@aliyun.com; zhchr@cdut.edu.cn

${ }^{b}$ College of Energy, Chengdu University of Technology, Chengdu 610059, Sichuan, China 


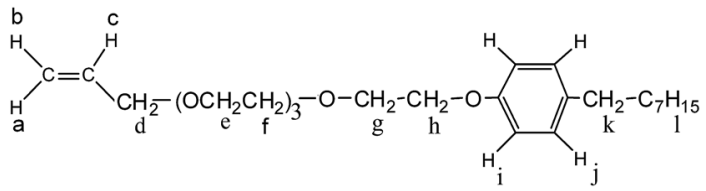

Scheme 1 Schematic molecular structure of AE.

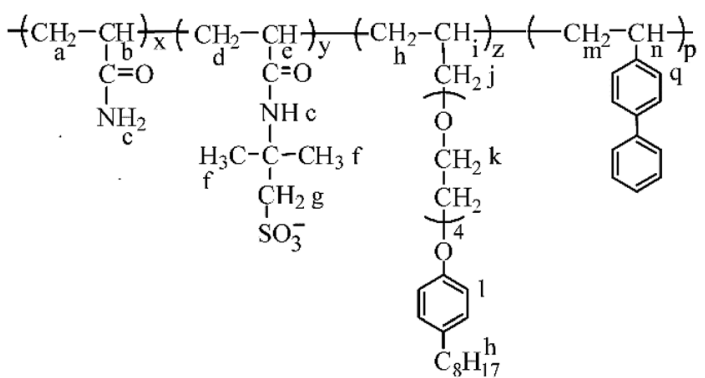

Scheme 2 Schematic molecular structure of PASV.

salinities. ${ }^{24}$ Formation water contains some salinity for all oil reservoirs, and their salinities are different. No polymer exhibiting excellent viscoelastic behavior in brine solutions with salinities being higher than $50 \mathrm{~g} \mathrm{~L}^{-1}$ as well as in aqueous solutions has yet been reported in the literature.

In this article, in order to obtain an oil-flooding polymer that can exhibit excellent thickening and viscoelastic properties in aqueous and brine solutions, a novel macromonomer, allylcapped octylphenoxy poly(ethylene oxide) (PEO) with the polymerization degree of 4 ( $\mathrm{AE}$, Scheme 1), was incorporated into a tetra-polymer. Then, a novel polymer (PASV, Scheme 2) was synthesized by copolymerizing acrylamide (AM), sodium 2acrylamido-2-methylpropanesulphonate (NaAMPS), vinyl biphenyl (VP), and AE. Introduction of an AE unit can enhance remarkably the rigidity of polymer chains. AM is commonly used in EOR, and its water-solubility and copolymerization activity are good. NaAMPS is a salt-tolerant anionic monomer; it can improve the water solubility of polymers and expand polymer chains because of strong charge repulsion. VP is used as a hydrophobic monomer; only when the biphenyl group is present together with the octylphenyl group can the strong intermolecular hydrophobic associations be formed. Otherwise, the apparent viscosities are very low in aqueous and brine solutions for the poly(AM/NaAMPS/AE) ter-polymer because the hydrophilicity of the PEO chains interferes with the intermolecular associations of the octylphenyl group.

In China, total salinities are approximately $70 \mathrm{~g} \mathrm{~L}^{-1}$ and formation temperatures are about $65{ }^{\circ} \mathrm{C}$ for some oil reservoirs where the polymer oil-flooding technology can be applied. So, the thickening properties were investigated for PASV in water and in $70 \mathrm{~g} \mathrm{~L}^{-1} \mathrm{NaCl}$; in order to reveal the correlation between shear behavior and associated structures for polymer solutions at high pressures, the consecutive shear behaviors of a PASV brine solution with $70 \mathrm{~g} \mathrm{~L}^{-1} \mathrm{NaCl}$ were studied at $65^{\circ} \mathrm{C}$ with the pressures of atmospheric pressure to $20 \mathrm{MPa}$ as well as at atmospheric temperature and pressure. Moreover, effects of polymer concentration, $\mathrm{NaCl}$ concentration, and sodium dodecyl benzene sulfonate (SDBS) concentration on the viscoelastic properties of PASV solutions were investigated.

\section{Experimental section}

\section{Materials}

Acrylamide (AM) was recrystallized twice using chloroform. 2Acrylamido-2-methylpropanesulphonate (AMPS) was obtained from Lubrizol Co. (USA). Allyl chloride and vinyl biphenyl were purchased from Acros Organics Company. HPAM (intrinsic viscosity $[\eta]: 49.68 \mathrm{dL} \mathrm{g}^{-1}$, hydrolysis degree: $25 \%$; according to the equation $[\eta]=3.20 \times 10^{-4}{\overline{M_{\mathrm{w}}}}^{0.707}$, weight-average molecular weight $\overline{M_{\mathrm{w}}}: 2.20 \times 10^{7} \mathrm{~g} \mathrm{~mol}^{-1}$ ) was purchased from DaQing Polymer Company in China. Tetrahydrofuran (THF) was dried by anhydrous sodium sulfate $\left(\mathrm{Na}_{2} \mathrm{SO}_{4}\right)$ before using. AM, THF, sodium dodecyl benzene sulfonate (SDBS), sodium dodecyl sulfate (SDS), $\mathrm{NaCl}$, and other reagents were analytically pure, and were supplied by Chengdu Kelong Chemical Co. (China). The water used was distilled twice.

\section{Instruments and methods}

A solution of PASV in $\mathrm{D}_{2} \mathrm{O}$ was measured with a $400 \mathrm{MHz}$ Inova400 instrument (Varian Co., USA) at room temperature. The FTIR spectra were analyzed using a Nicolet-560 FT-IR spectrophotometer with a resolution capacity of $1 \mathrm{~cm}^{-1}$, and a $\mathrm{KBr}$ pellet was prepared containing the purified polymer sample. A $0.6 \mathrm{~mm}$ Ubbelohde capillary viscometer was used to measure the intrinsic viscosities $[\eta]$ of HPAM and PASV in a $1.0 \mathrm{~mol} \mathrm{~L}^{-1}$ sodium nitrate solution at $30.0 \pm 0.1{ }^{\circ} \mathrm{C}$. The apparent viscosities of polymer aqueous and brine solutions were measured at $30{ }^{\circ} \mathrm{C}$ with a DV III R27112E viscometer (Brookfield Co., USA) at a shear rate of $7.34 \mathrm{~s}^{-1}$.

Atomic force micrographs were obtained using Nanoscope Multimode 8 \& Explore atomic force microscope (Veeco Instrument Co., USA). All samples were covered on mica flakes and dried naturally in a desiccator containing anhydrous silica gel to form a thin film at a temperature of $25-30{ }^{\circ} \mathrm{C}$.

Steady-state shear and viscoelastic measurements were performed with a HAAKE MARS modular advanced rheometer system (Thermo Fisher Scientific, Germany) equipped with cone-plate geometry (angle $2^{\circ}$ and diameter $60 \mathrm{~mm}$ ). A thermostatic system was used to keep the measured solutions at a constant temperature of $(30 \pm 0.1)^{\circ} \mathrm{C}$ or $(65 \pm 0.1)^{\circ} \mathrm{C}$. Varied pressures were controlled by a pressurization system. An optimum strain was first determined before the dynamic measurements, all samples were measured for $34 \mathrm{~min}$, and the angular frequency ranged from 0.05 to $50 \mathrm{rad} \mathrm{s}^{-1}$. During steady shear measurements, every sample was measured for $16 \mathrm{~min}$ for a shear cycle, and the shear rate ranged from 0.1 to $100 \mathrm{~s}^{-1}$. The measured data of steady shear were fitted according to the power law model:

$$
\tau=K \gamma^{n} \text { and } \eta_{\text {app }}=\tau / \gamma=K \gamma^{n-1}
$$


where $\tau$ is the shear stress, $\eta_{\text {app }}$ is the apparent viscosity, $\gamma$ is the shear rate, $K$ is the consistency coefficient, and $n$ is the powerlaw index.

\section{Synthesis of the AE macro-monomer}

Poly(ethylene oxide) (PEO) octylphenyl ether with the polymerization degree of 4 (OP-4, $20 \mathrm{~g}, 0.05219 \mathrm{~mol}$ ) and $31 \mathrm{~mL}$ of dry THF were, respectively, added into a $250 \mathrm{~mL}$ three-necked flask. A mixture of $\mathrm{Na}(1.5005 \mathrm{~g}, 0.06524 \mathrm{~mol}$, Na/OP-4 $1.25: 1$, mole ratio) and $10 \mathrm{~mL}$ of dry THF was then added slowly to the flask. The reaction mixture was stirred for $3 \mathrm{~h}$ at room temperature; meanwhile the flask was purged with the nitrogen gas. After that, a solution of allyl chloride (3.3305 g, $0.04349 \mathrm{~mol}, \mathrm{OP}-4 /$ allyl chloride $1.2: 1$, mole ratio) in $20 \mathrm{~mL}$ of dry THF (the total mass percentage of OP-4 and allyl chloride in reactant solution: $30 \%$ ) was added dropwise. Finally, the reaction solution was heated and refluxed for $48 \mathrm{~h}$. When the reaction ended, the crude product solution cooled naturally to room temperature, and then it was concentrated by a rotatory evaporator under vacuum until THF was removed entirely. Finally, the crude product was purified by column chromatography (ethyl acetate/ethanol $25: 1, \mathrm{v} / \mathrm{v}$ ) to give $8.3170 \mathrm{~g}$ of pure $\mathrm{AE}$ as a buff liquid (45.20\% yield).

The ${ }^{1} \mathrm{H}-\mathrm{NMR}$ shifts $\delta(\mathrm{ppm})$ for AE are as follows: $5.269(\mathrm{~d}$, $\left.1 \mathrm{H}, \mathrm{H}^{\mathrm{a}}\right), 5.173\left(\mathrm{~d}, 1 \mathrm{H}, \mathrm{H}^{\mathrm{b}}\right), 5.920\left(\mathrm{dd}, 1 \mathrm{H}, \mathrm{H}^{\mathrm{c}}\right), 4.027\left(\mathrm{~s}, 2 \mathrm{H}, \mathrm{H}^{\mathrm{d}}\right)$, 3.586-3.729 (m, 12H, $\left.\mathrm{H}^{\mathrm{e}}-\mathrm{H}^{\mathrm{f}}\right), 3.859\left(\mathrm{~s}, 2 \mathrm{H}, \mathrm{H}^{\mathrm{g}}\right), 4.122\left(\mathrm{~s}, 2 \mathrm{H}, \mathrm{H}^{\mathrm{h}}\right)$, $6.831\left(\mathrm{~d}, 2 \mathrm{H}, \mathrm{H}^{\mathrm{i}}\right), 7.216\left(\mathrm{~d}, 2 \mathrm{H}, \mathrm{H}^{\mathrm{j}}\right), 2.171\left(\mathrm{~s}, 2 \mathrm{H}, \mathrm{H}^{\mathrm{k}}\right), 0.464-1.584$ $\left(\mathrm{m}, 15 \mathrm{H}, \mathrm{H}^{\mathrm{l}}\right)$. The FTIR absorption peaks $\left(\mathrm{cm}^{-1}\right)$ are $\mathrm{C}=\mathrm{C}$ of $\mathrm{CH}_{2}=\mathrm{CH}$ stretch, 1648.23; $=\mathrm{C}-\mathrm{H}$ of $\mathrm{CH}_{2}=\mathrm{CH}$ stretch, 3060.47; $=\mathrm{C}-\mathrm{H}$ of $\mathrm{CH}_{2}=\mathrm{CH}$ bending, 924.07; aromatic $\mathrm{C}=\mathrm{C}$ stretch, 1610.07, 1586.52, 1510.19; aromatic $=\mathrm{C}-\mathrm{H}$ bending, 829.23; $-\mathrm{CH}_{3},-\mathrm{CH}_{2}$ stretch, 2960.21, 2870.23; $-\mathrm{CH}_{3},-\mathrm{CH}_{2}$ bonding, 1460.32, 1350.17; - $\left(\mathrm{CH}_{2}\right)_{7}$ - bending, 746.15; C-O-C stretch, 1120.23; =C-O of phenol stretch, 1250.09.

\section{Synthesis of the PASV polymer}

The PASV polymer was synthesized by aqueous free-radical copolymerization. ${ }^{20} \mathrm{AM}(4.0 \mathrm{~g}, 0.0563 \mathrm{~mol}, 90.3 \mathrm{~mol} \%$ ) and AMPS (1.0346 g, $0.00499 \mathrm{~mol}, 8 \mathrm{~mol} \%$ ) were added to a $100 \mathrm{~mL}$ three-necked round-bottomed flask. This flask was equipped with a mechanical stirrer, a nitrogen inlet, and an outlet. Then,
$29.16 \mathrm{~mL}$ of distilled water was also added and the mixture was stirred for $0.5 \mathrm{~h}$ until the added monomer solids were completely dissolved in water. The $\mathrm{pH}$ value of the reaction solution was controlled within 5-7 using $\mathrm{NaOH}$. Sodium dodecyl sulfate (SDS) (0.9042 g) was added to the flask with stirring. Finally, AE (0.1592 g, $\left.3.7636 \times 10^{-4} \mathrm{~mol}, 0.6 \mathrm{~mol} \%\right)$ and VP (0.1244 g, $\left.6.9000 \times 10^{-4} \mathrm{~mol}, 1.1 \mathrm{~mol} \%\right)$ were, respectively, added to the flask. The flask was purged with $\mathrm{N}_{2}$ for half an hour to exclude oxygen gas. After this, the reactant solution was heated to $60{ }^{\circ} \mathrm{C}$ in a thermostatic water bath under a nitrogen atmosphere, and $0.98 \mathrm{~mL}$ of $0.02 \mathrm{~mol} \mathrm{~L}^{-1} \mathrm{~K}_{2} \mathrm{~S}_{2} \mathrm{O}_{8}$ solution was added to the solution. The mass percent composition of total monomer in water is $15 \%$. After the polymerization proceeded for $32 \mathrm{~h}$ at $60{ }^{\circ} \mathrm{C}$, a transparent polymer gel was produced. The PASV polymer gel was dissolved in $800 \mathrm{~mL}$ of distilled water, and then $900 \mathrm{~mL}$ of propanol was added to the aqueous solution with stirring to precipitate the polymer. The polymer was extracted with ethanol by a Soxhlet extractor for 2 days. Finally, the polymers were dried in vacuo at $50{ }^{\circ} \mathrm{C}$ for three days.

The ${ }^{1} \mathrm{H}-\mathrm{NMR}$ shifts $\delta(\mathrm{ppm})$ for PASV are $\mathrm{H}^{\mathrm{a}}, \mathrm{H}^{\mathrm{d}}, \mathrm{H}^{\mathrm{m}}, 1.651$; $\mathrm{H}^{\mathrm{b}}, \mathrm{H}^{\mathrm{e}}, 2.248 ; \mathrm{H}^{\mathrm{c}}, 4.793 ; \mathrm{H}^{\mathrm{f}}, \mathrm{H}^{\mathrm{i}}, 1.497 ; \mathrm{H}^{\mathrm{g}}, 3.462 ; \mathrm{H}^{\mathrm{h}}, 1.185 ; \mathrm{H}^{\mathrm{j}}$, $\mathrm{H}^{\mathrm{n}}, 3.221 ; \mathrm{H}^{\mathrm{k}}, 3.650-4.024 ; \mathrm{H}^{\mathrm{l}}, 7.026 ; \mathrm{H}^{\mathrm{q}}$, 7.849. FT-IR absorption peaks $\left(\mathrm{cm}^{-1}\right)$ are $-\mathrm{N}-\mathrm{H}$ stretch, 3396.09; aromatic $=\mathrm{C}-\mathrm{H}$ stretch, 3199.38; $\mathrm{C}=\mathrm{O}$ stretch, 1666.22; $-\mathrm{CH}_{3},-\mathrm{CH}_{2},-\mathrm{CH}$ stretch, 2844.57, 2931.32, 2777.02; $-\mathrm{CH}_{3},-\mathrm{CH}_{2},-\mathrm{CH}$ bending, 1405.40, 1452.17, 1337.81; $\mathrm{C}=\mathrm{C}$ in phenyl stretch, 1601.35; C-O of poly(ethylene oxide) (PEO) stretch, 1135.12; C-O of phenol stretch, 1187.95; $-\mathrm{SO}_{3}{ }^{-}: 1039.46,626.76$. The intrinsic viscosity $([\eta])$ is $5.23 \mathrm{dL} \mathrm{g}^{-1}$.

\section{Results and discussion}

\section{Effect of polymer concentration on apparent viscosity}

Fig. 1a displays the plots of apparent viscosity versus polymer concentration in the ranges of $0.1-2.0 \mathrm{~g} \mathrm{~L}^{-1}$ for PASV and HPAM in water and in a $70 \mathrm{~g} \mathrm{~L}^{-1} \mathrm{NaCl}$ solution, and it is enlarged to obtain Fig. $1 \mathrm{~b}$ in the ranges of $0.1-0.8 \mathrm{~g} \mathrm{~L}^{-1}$. For PASV in water, the critical association concentration $\left(C_{\mathrm{p}}^{*}\right)$ is $0.7 \mathrm{~g} \mathrm{~L}^{-1}$ (Fig. 1b), above which the apparent viscosity increases sharply with increasing polymer concentration. In addition, PASV shows good thickening behavior in aqueous solution; for example, the
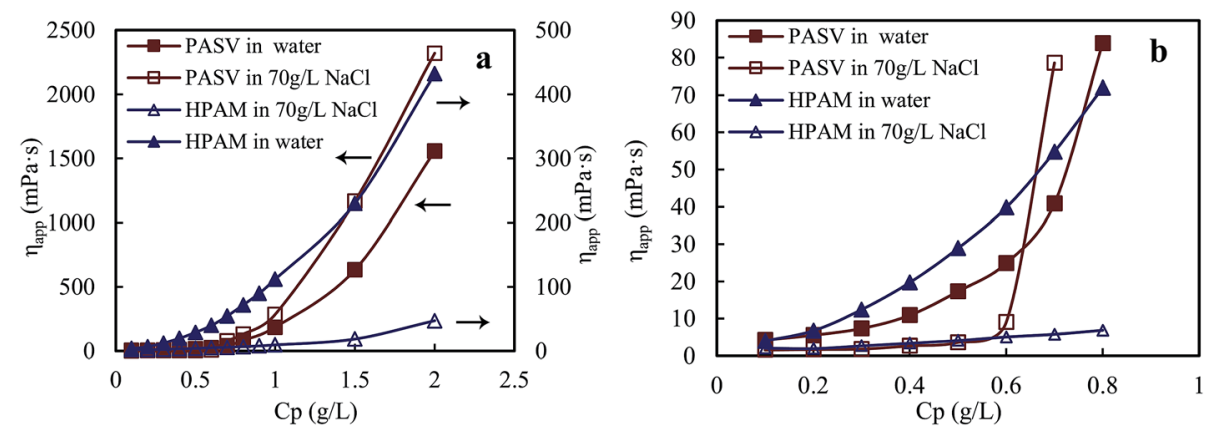

Fig. 1 Effect of polymer concentration on apparent viscosities of aqueous and brine solutions. (a) Polymer concentration: $0.1-2.0 \mathrm{~g} \mathrm{~L}{ }^{-1}$; (b) polymer concentration: $0.1-0.8 \mathrm{~g} \mathrm{~L}^{-1}$. 


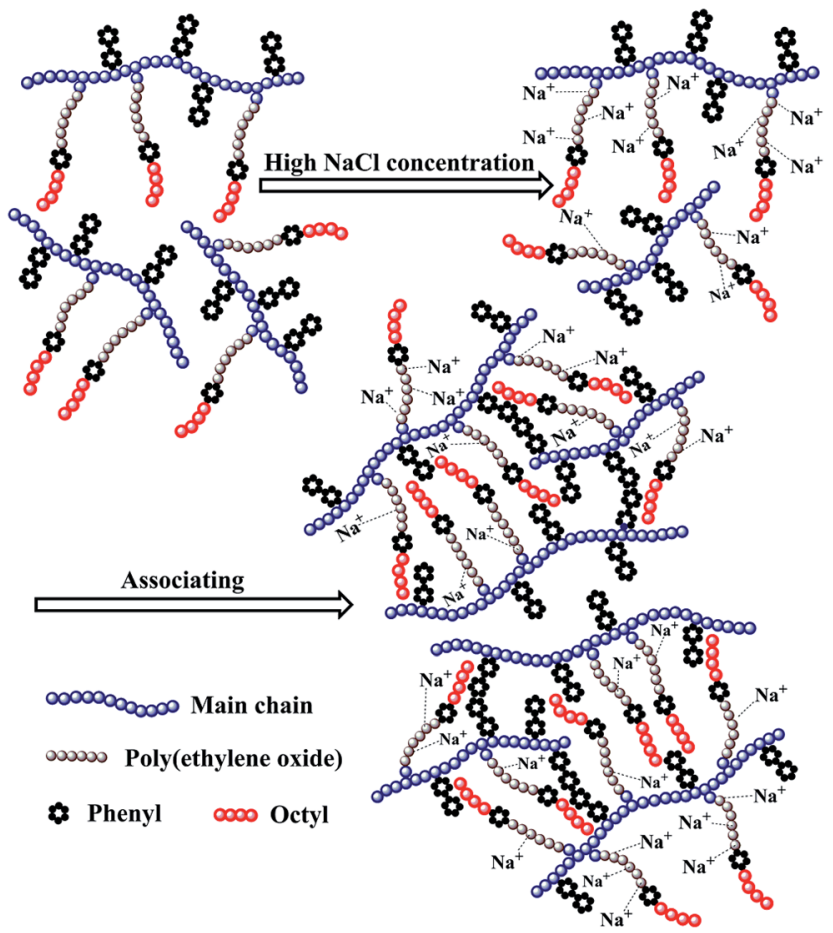

Scheme 3 Schematic structure of thickening induced by salt for PASV.

apparent viscosity reaches $1558 \mathrm{mPa} \mathrm{s}$ at the polymer concentration of $2.0 \mathrm{~g} \mathrm{~L}^{-1}$. With the addition of $70 \mathrm{~g} \mathrm{~L}^{-1} \mathrm{NaCl}$, the $C_{\mathrm{p}}^{*}$ is decreased to $0.6 \mathrm{~g} \mathrm{~L}^{-1}$. Moreover, the apparent viscosities of the PASV brine solutions are much higher than those of the aqueous PASV solutions above $0.6 \mathrm{~g} \mathrm{~L}^{-1}$. For example, the apparent viscosity is $2320 \mathrm{mPa}$ s for the $2.0 \mathrm{~g} \mathrm{~L}^{-1}$ PASV brine solution. However, for HPAM in water, the solution viscosity gradually increases with an increase in polymer concentration. The apparent viscosities are not high at all polymer concentrations. For example, the viscosity is merely $431.9 \mathrm{mPa} \mathrm{s}$ in $2.0 \mathrm{~g} \mathrm{~L} \mathrm{~L}^{-1}$ HPAM. Compared with the same aqueous HPAM solutions, the apparent viscosities of the brine solutions decrease dramatically.

The above mentioned plots indicate that the strong intermolecular hydrophobic associations of octylphenol and biphenyl groups were formed for PASV in water. This was further verified by the associated AFM images. With the addition of a large amount of $\mathrm{NaCl}$, the $\mathrm{Na}^{+}$ions complex with the $\mathrm{C}-\mathrm{O}$ bonds in the $\mathrm{PEO}$ side chains, which results in a decrease of hydrophilicity of the PEO chains. So, the intermolecular associations among the PASV chains are strengthened and the viscosities increase remarkably (Scheme 3). By comparison, although the molecular-weight of the HPAM polymer is superhigh, this polymer does not contain hydrophobic groups. So, it does not display a $C_{\mathrm{p}}^{*}$ in water or in $70 \mathrm{~g} \mathrm{~L}^{-1} \mathrm{NaCl}$, and with the addition of $70 \mathrm{~g} \mathrm{~L}^{-1} \mathrm{NaCl}$ their apparent viscosities are reduced sharply at all polymer concentrations because of charge shielding.

Fig. 2a and b show the AFM images of the film made using an aqueous $0.5 \mathrm{~g} \mathrm{~L}^{-1}$ PASV solution. Some expanded polymer chain bundles are displayed for this solution, which shows that associated structures are formed. This also suggests that the PASV chains are stretched in aqueous solution because of the incorporation of the VP and AE units. As the polymer concentration is increased to $0.7 \mathrm{~g} \mathrm{~L}^{-1}$, the expanded polymer chains associated with each other through stronger intermolecular hydrophobic associations to form more supra-molecular structures (see Fig. 3), and so the apparent viscosity increases from $17.3 \mathrm{mPa}$ s of the $0.5 \mathrm{~g} \mathrm{~L}^{-1}$ PASV solution to $44.9 \mathrm{mPa}$ s. As seen in Fig. 4, continuous associated structures are observed for the film made using the aqueous $1.0 \mathrm{~g} \mathrm{~L}^{-1}$ PASV solution, resulting in a high apparent viscosity (186 $\mathrm{mPa}$ s). These images indicate that the expanded polymer chains are favorable for forming intermolecular hydrophobic associations.

\section{Influence of shear rate on apparent viscosity}

Atmospheric pressure. Fig. 5a and b display, respectively, the apparent viscosity as a function of shear rate upon three consecutive shear cycles for an aqueous $2.0 \mathrm{~g} \mathrm{~L}^{-1}$ PASV solution and a $2.0 \mathrm{~g} \mathrm{~L}^{-1}$ PASV brine solution with $70 \mathrm{~g} \mathrm{~L}^{-1} \mathrm{NaCl}$; the shear rate range is $0.1-100 \mathrm{rad} \mathrm{s}^{-1}$, and the measurement is at atmospheric pressure and $30{ }^{\circ} \mathrm{C}$. For the aqueous PASV solution, during the first shear process with an increase in shear rate, the apparent viscosity increases dramatically in a low shear rate range of $0.1-0.27 \mathrm{~s}^{-1}$ (Fig. 5a). This exhibits an obvious shear thickening behavior, and the maximum apparent viscosity is $24320 \mathrm{mPa}$. The apparent viscosity reduces sharply with further increasing shear rate from $0.27 \mathrm{~s}^{-1}$ to $4.28 \mathrm{~s}^{-1}$, and
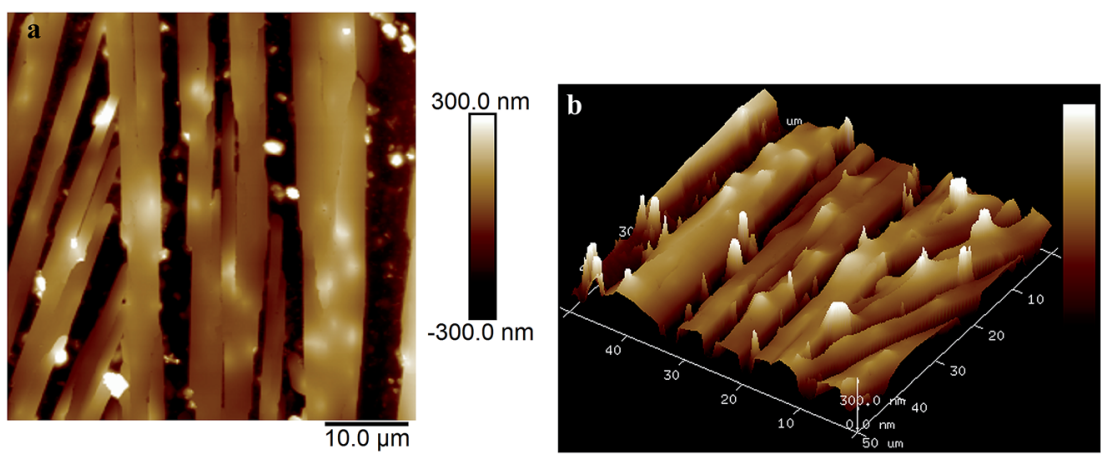

Fig. 2 AFM images of the film made using an aqueous $0.5 \mathrm{~g} \mathrm{~L}^{-1}$ PASV solution. (a) Planar morphology; (b) three-dimensional morphology. 


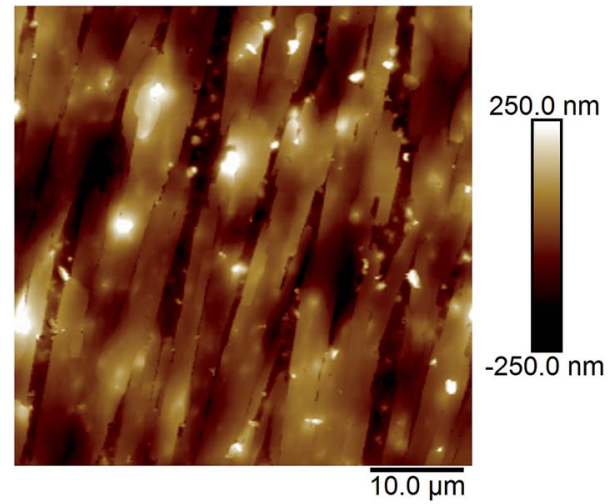

Fig. 3 AFM image of the film made using an aqueous $0.7 \mathrm{~g} \mathrm{~L}^{-1}$ PASV solution.

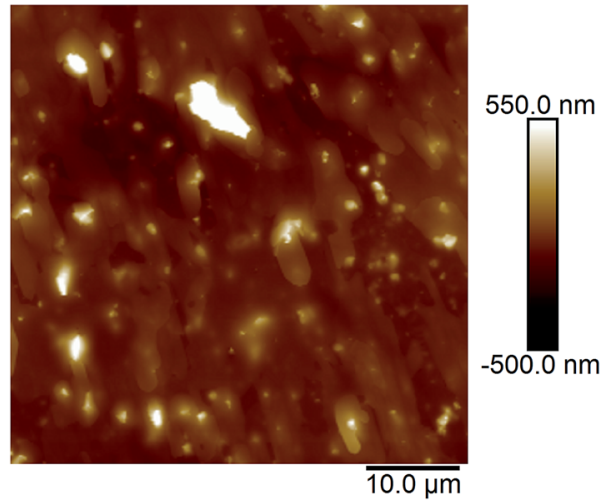

Fig. 4 AFM image of the film made using an aqueous $1.0 \mathrm{~g} \mathrm{~L}^{-1}$ PASV solution

then reduces slowly in a shear rate range of 4.28-42.19 $\mathrm{s}^{-1}$. Finally, the viscosity tends to constancy at higher shear rates. During the first shear reversion, upon slowly reducing the shear rate, the viscosity is almost equal to the primary one above $42.27 \mathrm{~s}^{-1}$, and then it increases remarkably with decreasing shear rate from 42.27 to $0.18 \mathrm{~s}^{-1}$ but obviously is lower than the primary viscosity. Finally, the viscosity is much higher than the primary one below $0.18 \mathrm{~s}^{-1}$. For the second shear process, the viscosity is almost the same as that during the first shear reversion at all shear rates, and it decreases with increasing shear rate; the solution exhibits pseudoplastic behavior. The plot of the third shear process overlaps with that of the corresponding shear reversion, and the viscosities during the third shear cycle are much higher than those during the first shear process below $0.13 \mathrm{~s}^{-1}$. Fig. $5 \mathrm{~b}$ shows that the brine solution exhibits similar shear thickening behavior to the above aqueous solution for the first shear process, but its maximum apparent viscosity is much higher than that of the aqueous solution. In addition, the apparent viscosities in the first shear process are much higher than those in the other five shear measurements below $18.02 \mathrm{~s}^{-1}$, and the apparent viscosities in the five shear measurements are almost the same above $0.89 \mathrm{~s}^{-1}$.

The above experimental data indicate that the polymer chains are stretched upon shearing at the low shear rates of 0.1$0.27 \mathrm{~s}^{-1}$ during the first shear process for the PASV aqueous and brine solutions. So, the intermolecular hydrophobic associations are enhanced, resulting in the formation of more associated structures. These supramolecular structures become looser and their hydrodynamic volumes become larger because of suitable shearing. As a result, their apparent viscosities are very high and increase dramatically with increasing shear rate. In addition, this suggests that the expansion of polymer chains is greatly favorable for the formation of intermolecular associations. Then as the shear rate is further increased, some large associated structures are disrupted to form smaller aggregates, resulting in a shear thinning behavior. Finally, when the shear rate is higher than $42 \mathrm{~s}^{-1}$, some small aggregates are also destroyed in the aqueous and brine solutions, leading to a constant viscosity. The repetitious shear cycles indicate that the apparent viscosities of the PASV aqueous and brine solutions are mainly dependent on intermolecular hydrophobic associations and that the associations can be reversible. However, some hydrophobic-associated structures cannot be reformed immediately.

Nowadays, HPAM polymers are still widely applied in EOR of oil fields. Thus, shear behaviors of aqueous and brine solutions containing HPAM (weight-average molecular weight: $2.2 \times$ $10^{7} \mathrm{~g} \mathrm{~mol}^{-1}$, hydrolysis degree: $25 \%$ ) are measured to reveal differences between the shear behaviors of the super-highmolecular-weight polymers and that of associated PASV with low-molecular-weight. The intrinsic viscosity ([ $\eta])$ of PASV is $5.23 \mathrm{dL} \mathrm{g}^{-1}$, but $[\eta]$ of HPAM is $49.68 \mathrm{dL} \mathrm{g}^{-1}$ and is much higher than that of PASV. Fig. 6a shows the apparent viscosity as
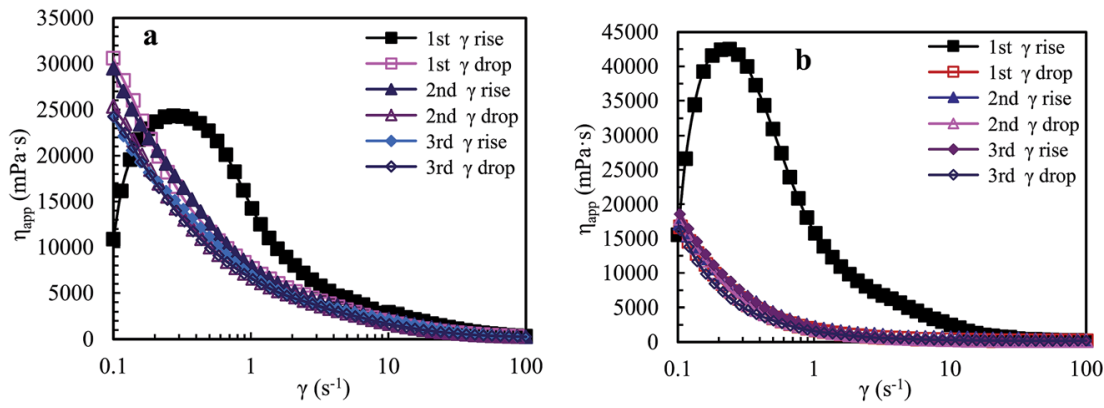

Fig. 5 Influence of shear rate on apparent viscosities of an aqueous $2.0 \mathrm{~g} \mathrm{~L}^{-1} \mathrm{PASV}$ solution (a) and of a $2.0 \mathrm{~g} \mathrm{~L}^{-1} \mathrm{PASV}_{\text {brine solution with } 70 \mathrm{~g} \mathrm{~L}}^{-1}$ $\mathrm{NaCl}\left(\right.$ b) at atmospheric pressure and $30^{\circ} \mathrm{C}$. 

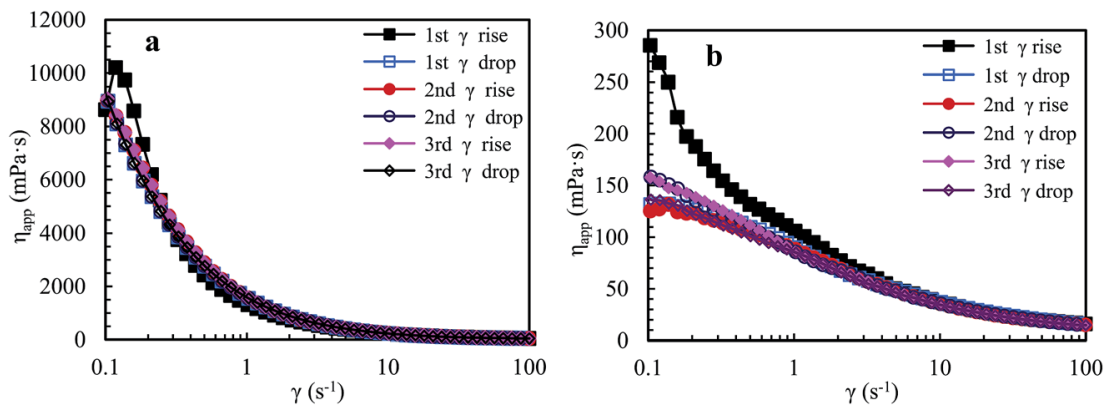

Fig. 6 Influence of shear rate on the apparent viscosities of an aqueous $2.0 \mathrm{~g} \mathrm{~L}^{-1} \mathrm{HPAM}$ solution (a) and of a $2.0 \mathrm{~g} \mathrm{~L}^{-1} \mathrm{HPAM}$ brine solution with $70 \mathrm{~g} \mathrm{~L}^{-1} \mathrm{NaCl}$ (b) at atmospheric pressure and $30^{\circ} \mathrm{C}$.

a function of shear rate upon three consecutive shear cycles for an aqueous $2.0 \mathrm{~g} \mathrm{~L}^{-1}$ HPAM solution. For the first shear process with increasing shear rate, the polymer solution displays shear thickening behavior at very low shear rates of $0.1-0.15 \mathrm{~s}^{-1}$, then a prominent shear thinning behavior is followed, and finally the apparent viscosity tends to constancy at shear rates higher than $11.6 \mathrm{~s}^{-1}$. The apparent viscosities in the first shear process are higher than those in the other five shear measurements below $0.21 \mathrm{~s}^{-1}$. Additionally, the apparent viscosities are almost the same during the range of $0.1-100 \mathrm{~s}^{-1}$ except the first shear process.

Fig. 6b shows the variation of apparent viscosity with shear rate upon three consecutive shear cycles for a $2.0 \mathrm{~g} \mathrm{~L}^{-1}$ HPAM brine solution with $70 \mathrm{~g} \mathrm{~L}^{-1} \mathrm{NaCl}$. The apparent viscosities are far lower than those of the above mentioned aqueous HPAM solution at all shear rates. For the first shear process, this brine solution does not exhibit shear thickening behavior at very low shear rates, but exhibits a pseudoplastic behavior when shear rates are lower than $42.2 \mathrm{~s}^{-1}$. For the following five shear measurements, the viscosities are almost identical above $0.8 \mathrm{~s}^{-1}$; they decrease gradually with increasing shear rate, and then almost do not vary above $42.5 \mathrm{~s}^{-1}$, exhibiting Newtonian fluid behavior.

HPAM aqueous and brine solutions show different shear behaviors from the PASV solutions, especially for brine solutions. This is due to the difference of thickening mechanisms for the two types of water-soluble polymers. For HPAM solutions, the building of apparent viscosities are determined by molecular weights of HPAM and the aggregation of polymer chains via hydrogen-bond interactions. However, for the PASV polymer with low-molecular-weight, its thickening performance depends on intermolecular hydrophobic associations of the octylphenyl groups and the biphenyl groups. So, the PASV polymer displays prominent shear thickening behaviors in the brine solution with a high $\mathrm{NaCl}$ concentration as well as in aqueous solution at very low shear rates. Moreover, the apparent viscosities of the PASV solutions are much higher than those of the HPAM solutions in the whole shear rate range. In addition, the linear polymer chains of HPAM are greatly coiled by the addition of a large amount of $\mathrm{NaCl}$ because of electrostatic shielding by $\mathrm{Na}^{+}$ions on the $-\mathrm{COO}^{-}$groups along polymer chains. As a result, the aggregation of polymer chains is destroyed, which leads to very low apparent viscosities.
High pressures. Presently, EOR techniques are commonly applied under high pressures of 5-20 MPa for all oil fields, but shear behaviors of oil-flooding polymers at high pressures have not yet been reported. Therefore, it is necessary to investigate shear behaviors of the PASV solution at high pressures. The formation temperature is circa $65^{\circ} \mathrm{C}$ for some oil reservoirs with high salinities in China, and so the temperature is $65^{\circ} \mathrm{C}$ in our shear measurements. Fig. 7a-d show the apparent viscosity as a function of shear rate upon two consecutive shear cycles for a $2.0 \mathrm{~g} \mathrm{~L}^{-1}$ PASV brine solution with $70 \mathrm{~g} \mathrm{~L}^{-1} \mathrm{NaCl}$ at different pressures, respectively. As shown in Fig. 7a, the PASV brine solution displays an obvious shear thickening behavior during consecutive shear cycles at atmospheric pressure. For the first reversion, the viscosity is almost equal to the primary ones above $11.7 \mathrm{~s}^{-1}$, but is obviously higher than the primary ones below $11.7 \mathrm{~s}^{-1}$. For example, at the shear rate of $0.1 \mathrm{~s}^{-1}$, the apparent viscosities in the first shear and reversion processes are, respectively, $7899 \mathrm{mPa} \mathrm{s}$ and $16982 \mathrm{mPa}$ s. Moreover, during the second shear cycle, the apparent viscosities are almost the same as those in the first reversion at all shear rates; in addition, as shear rate is increased, the apparent viscosity reduces prominently below $0.6 \mathrm{~s}^{-1}$, then decreases slowly during the range of $0.6-5.7 \mathrm{~s}^{-1}$, and finally tends to constancy above $5.7 \mathrm{~s}^{-1}$. These plots indicate that some large hydrophobic associated structures are disrupted seriously at high shear rates but larger hydrophobic associated structures are reformed rapidly at lower shear rates during shear reversion. This is because expansion of the polymer chains is improved after shearing, and so the intermolecular hydrophobic associations still become stronger at a high temperature of $65^{\circ} \mathrm{C}$.

The PASV brine solution at high pressures exhibits similar shear thickening behaviors to that at atmospheric pressure (see Fig. 7b-d). This shear thickening performance becomes more remarkable with increasing pressure. For example, at pressures of $15 \mathrm{MPa}$ and $20 \mathrm{MPa}$, the apparent viscosities during the second shear reversion are much higher than those during the other three shear processes at shear rates of 0.1-1 $\mathrm{s}^{-1}$. In addition, the apparent viscosities increase with increasing pressure from $10 \mathrm{MPa}$ to $20 \mathrm{MPa}$ at the same shear rates being lower than $1 \mathrm{~s}^{-1}$ during the four shear processes. These results suggest that the octylphenol and biphenyl groups associate more easily with each other at high pressures and that the intermolecular van der Waals interactions of hydrophobic 

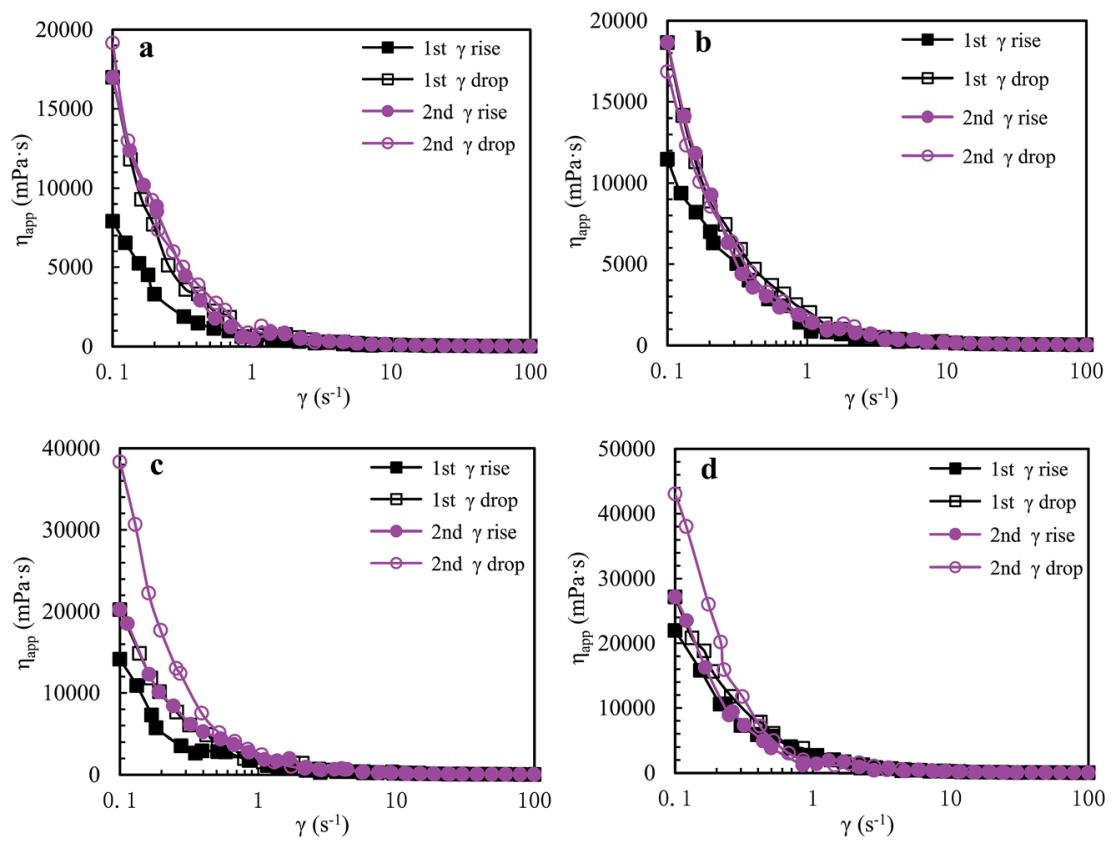

Fig. 7 Influence of shear rate on apparent viscosities of a $2.0 \mathrm{~g} \mathrm{~L}^{-1}$ PASV brine solution with $70 \mathrm{~g} \mathrm{~L}^{-1} \mathrm{NaCl}$ at different pressures and $65^{\circ} \mathrm{C}$. (a) $0 \mathrm{MPa}$; (b) $10 \mathrm{MPa}$; (c) $15 \mathrm{MPa}$; and (d) $20 \mathrm{MPa}$.

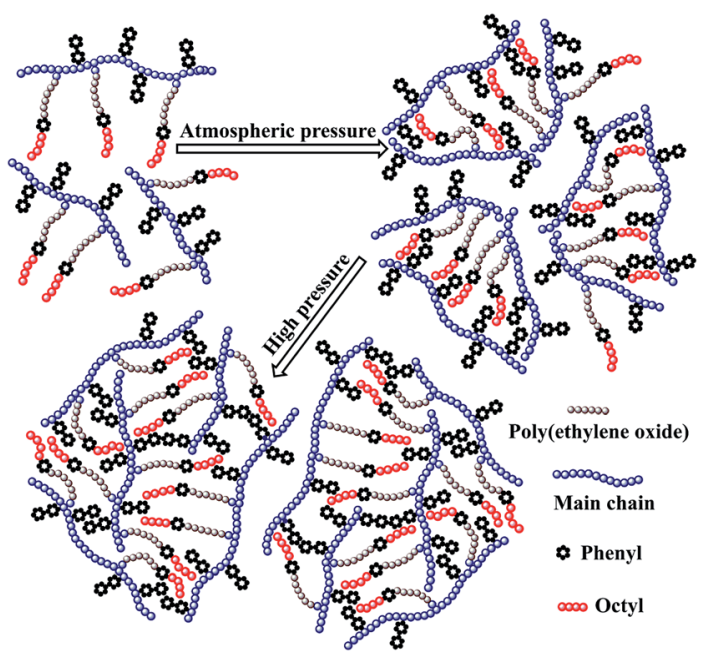

Scheme 4 Schematic structure of pressure-thickening for PASV.

groups are strengthened remarkably with increasing pressure. As a result, larger associated aggregates are formed at higher pressures (Scheme 4). The pressure-thickening behavior is found at high pressures via the mentioned above four figures for the PASV brine solution. This is not reported in the literature. Thus, its apparent viscosities in oil reservoirs should be higher than those on the ground. In addition, the repetitious shear cycles indicate that high temperature and high pressure are beneficial to an immediate reformation of the hydrophobic associated structures disrupted after shearing at high shear rates and that the sizes of reformed hydrophobic associated structures are increased at low shear rates.

\section{Viscoelastic properties of PASV solutions}

Effect of polymer concentration. Fig. 8a displays the variation of elastic modulus $\left(G^{\prime}\right)$ and viscous modulus $\left(G^{\prime \prime}\right)$ with angular frequency for aqueous polymer solutions with different PASV concentrations; an angular frequency range is $0.05-50 \mathrm{rad}$ $\mathrm{s}^{-1}$, and the measurement is under the influence of a constant oscillatory strain. The viscoelastic parameters $G^{\prime}$ and $G^{\prime \prime}$ can characterize, respectively, the elastic and viscous properties of polymer solutions. As seen in Fig. 8a, the elastic and viscous moduli increase markedly with an increase in angular frequency for the four samples all over the angular frequency range. Moreover, for aqueous PASV solutions, as the polymer concentration is increased, $G^{\prime}$ and $G^{\prime \prime}$ increase dramatically. This shows that the increase of angular frequency and polymer concentration is favorable for the presence of elastic deformation and viscous performance. However, whether a polymer solution exhibits predominantly viscous behavior or elastic behavior depends on loss tangent $\tan \delta\left(G^{\prime \prime} / G^{\prime}\right)$. A polymer solution exhibits predominantly elastic behavior when $G^{\prime \prime} / G^{\prime}$ is less than 1 , otherwise it exhibits predominantly viscous behavior. So, the three aqueous solutions $\left(C_{\mathrm{p}}>1.0 \mathrm{~g} \mathrm{~L}^{-1}\right)$ exhibit predominantly outstanding elastic behavior over the measured frequencies and $G^{\prime \prime} / G^{\prime}$ are less than 1 . The aqueous $1.0 \mathrm{~g} \mathrm{~L}^{-1}$ PASV solution exhibits predominantly elastic behavior below $23.73 \mathrm{rad} \mathrm{s}^{-1}$, followed by viscous behavior. These results show that intermolecular hydrophobic associations of octylphenol and biphenyl groups have been formed at a polymer concentration of $1.0 \mathrm{~g} \mathrm{~L}^{-1}$. In addition, for the four solutions, with an increase in polymer concentration, the $G^{\prime \prime} / G^{\prime}$ values reduce and the elastic character is displayed more remarkably. This indicates that intermolecular hydrophobic associations are clearly strengthened with increasing polymer concentration. 

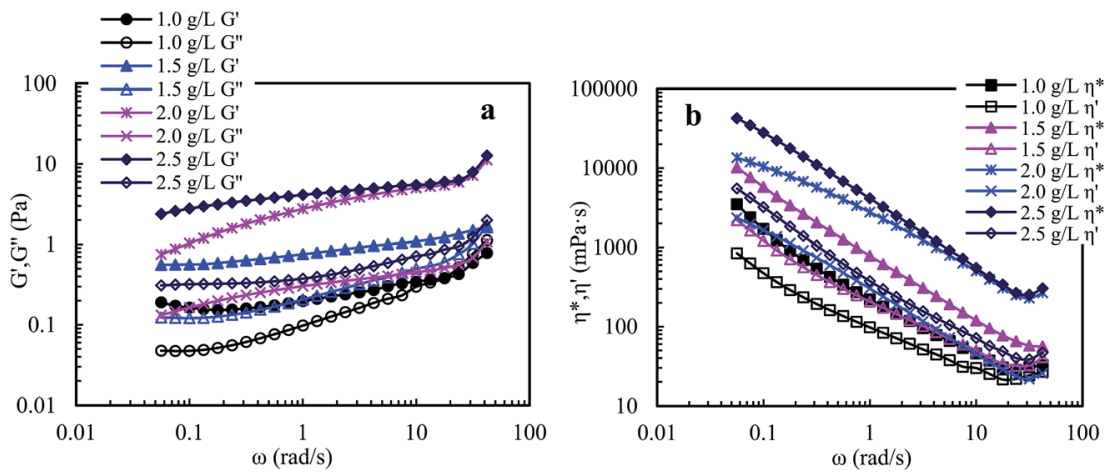

Fig. 8 Influence of angular frequency on elastic modulus $G^{\prime}$ and viscous modulus $G^{\prime \prime}$ (a), and on dynamic viscosity $\eta^{\prime}$ and complex viscosity $\eta^{*}$ (b) for aqueous PASV solutions with different polymer concentrations.

Elastic viscosity $\left(\eta^{\prime \prime}\right)$ and dynamic viscosity $\left(\eta^{\prime}\right)$ are, respectively, determined by elastic and viscous characters, and complex viscosity $\left(\eta^{*}\right)$ shows the comprehensive effect of viscous and elastic characters on the solution viscosity. Fig. 8b shows influence of angular frequency on $\eta^{\prime}$ and $\eta^{*}$ for aqueous PASV solutions with different polymer concentrations. For the four aqueous solutions, $\eta^{*}$ is much higher than $\eta^{\prime}$ over the measured angular frequencies. Moreover, the difference in value between $\eta^{*}$ and $\eta^{\prime}$ increases with increasing polymer concentration. However, as the angular frequency increases for all the solutions, $\eta^{*}$ and $\eta^{\prime}$ both decrease remarkably when the angular frequencies are lower than $30 \mathrm{rad} \mathrm{s}^{-1}$, and then increase. These plots further indicate that intermolecular hydrophobic associations are reinforced with an increase in polymer concentration. However, some associated structures are disrupted by shear, leading to a decrease in complex and dynamic viscosities, but the PASV chains are stretched at high angular frequencies.

Fig. 9 shows that the viscoelastic parameters vary with angular frequency for PASV brine solutions with $70 \mathrm{~g} \mathrm{~L}^{-1} \mathrm{NaCl}$ at different polymer concentrations. For $1.0 \mathrm{~g} \mathrm{~L}^{-1}$ PASV brine solution, $G^{\prime}$ reduced markedly with the addition of $\mathrm{NaCl}$, and the $G^{\prime \prime} / G^{\prime}$ values are higher than 1 when angular frequencies are lower than $3.0 \mathrm{rad} \mathrm{s}^{-1}$, exhibiting predominantly viscous behavior, and then are less than 1, displaying predominantly elastic behavior. The other three brine solutions exhibit predominantly elastic behavior over all the angular frequencies. Moreover, for four brine solutions, the $G^{\prime \prime} / G^{\prime}$ values reduce with increasing angular frequency, indicating that polymer chains expanded to exhibit more obvious elastic character. Compared with aqueous 1.5-2.5 $\mathrm{g} \mathrm{L}^{-1}$ PASV solutions, with the addition of a large amount of $\mathrm{NaCl}$, the three brine solutions do not lose elastic character; unexpectedly their elastic characters become more obvious. This suggests that larger hydrophobic associated structures are formed at the high $\mathrm{NaCl}$ concentration. So, the complex viscosities of these brine solutions (see Fig. 9b) are much higher than those of the corresponding aqueous solutions. As shown in Fig. 9b, $\eta^{*}$ is almost equal to $\eta^{\prime}$ at very low angular frequencies for $1.0 \mathrm{~g} \mathrm{~L}^{-1}$ PASV brine solutions, but $\eta^{*}$ is much higher than $\eta^{\prime}$ for the other three brine solutions over all the angular frequencies. These results indicate that some associated aggregates are destroyed by the addition of large amounts of $\mathrm{NaCl}$ at low PASV concentrations but larger associated structures are formed in brine solutions at high polymer concentrations because of the strengthened intermolecular associations induced by salt.

Effect of NaCl concentration. Fig. 10a displays the plots of $G^{\prime}$ and $G^{\prime \prime}$ versus angular frequency for $2.0 \mathrm{~g} \mathrm{~L}^{-1}$ PASV brine solutions with different $\mathrm{NaCl}$ concentrations. For a $40 \mathrm{~g} \mathrm{~L}^{-1} \mathrm{NaCl}$ solution, $G^{\prime \prime}$ is higher than $G^{\prime}$ below $3.1 \mathrm{rad} \mathrm{s}^{-1}$, and then almost equal to $G^{\prime}$, displaying predominantly viscous behavior. In addition, $G^{\prime \prime}$ and $G^{\prime}$ of this brine solution are far lower than
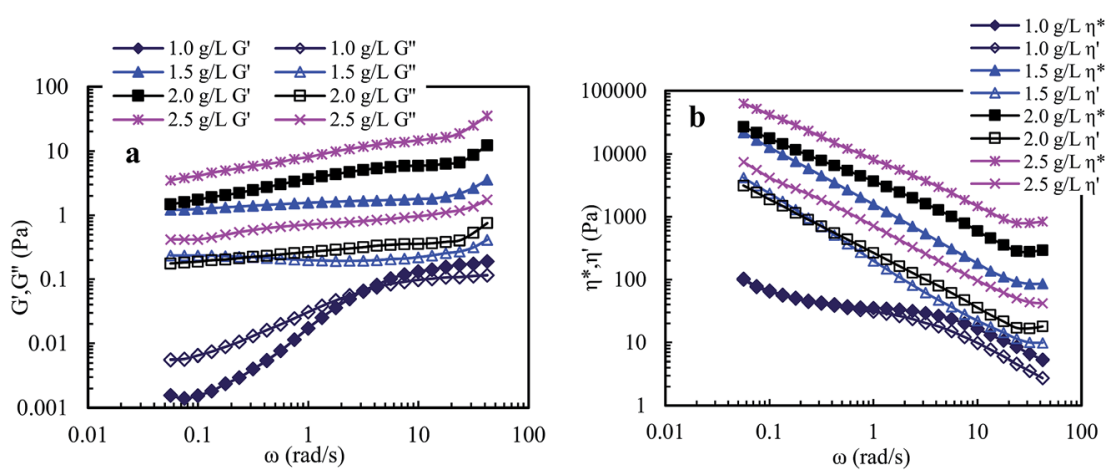

Fig. 9 Influence of angular frequency on elastic modulus $G^{\prime}$ and viscous modulus $G^{\prime \prime}$ (a), and on dynamic viscosity $\eta^{\prime}$ and complex viscosity $\eta^{*}$ (b) for PASV brine solutions with different polymer concentrations. $\mathrm{NaCl}$ concentration: $70 \mathrm{~g} \mathrm{~L}^{-1}$. 

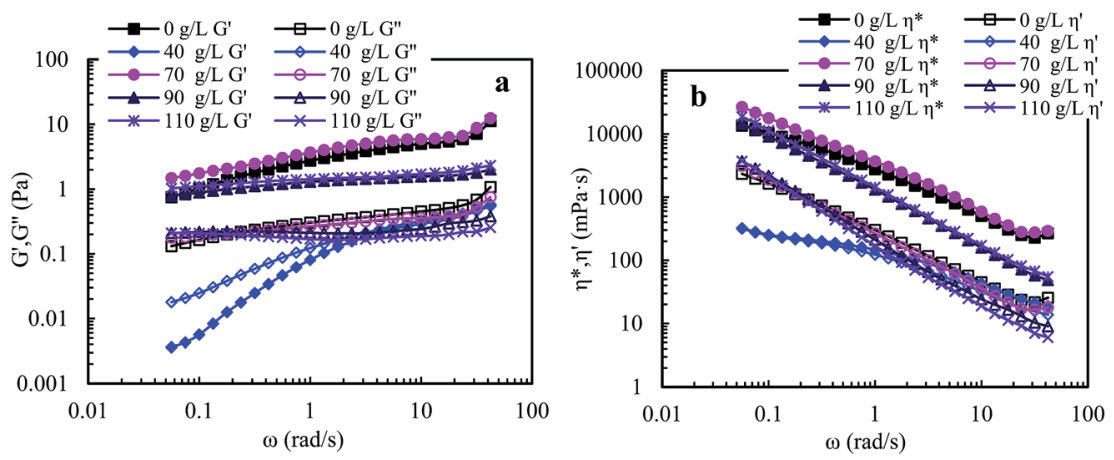

Fig. 10 Influence of angular frequency on elastic modulus $G^{\prime}$ and viscous modulus $G^{\prime \prime}$ (a), and on dynamic viscosity $\eta^{\prime}$ and complex viscosity $\eta^{*}$ (b) for $2.0 \mathrm{~g} \mathrm{~L}^{-1}$ PASV brine solutions with different $\mathrm{NaCl}$ concentrations.

those of the aqueous solution, which shows that the loss of viscoelastic character is tremendous. This is due to the strongest electrostatic shielding of repulsive interactions of $-\mathrm{SO}_{3}{ }^{-}$ groups along polymer chains and the disruption of many associated structures. For the other three brine solutions, $G^{\prime \prime}$ is dramatically lower than $G^{\prime}$, exhibiting predominantly obvious elastic behavior. Especially, for the $70 \mathrm{~g} \mathrm{~L}^{-1} \mathrm{NaCl}$ solution, the $G^{\prime \prime} / G^{\prime}$ values are the lowest among all brine solutions, and its elastic character is the most remarkable and even more obvious than that of the aqueous solution. So, the $\eta^{*}$ values of $70 \mathrm{~g} \mathrm{~L}^{-1}$ $\mathrm{NaCl}$ solution are also the highest among five solutions over all angular frequencies (Fig. 10b), displaying significant saltthickening behavior in the $\mathrm{NaCl}$ range of $40-70 \mathrm{~g} \mathrm{~L}^{-1}$. Moreover, although the $G^{\prime}$ values of the brine solutions decrease when $\mathrm{NaCl}$ concentrations are higher than $70 \mathrm{~g} \mathrm{~L}^{-1} \mathrm{NaCl}$, the brine solutions display predominantly outstanding elastic behavior in $90-110 \mathrm{~g} \mathrm{~L}^{-1} \mathrm{NaCl}$. The PASV chains are still expanded; the $\mathrm{Na}^{+}$ions can complex with the $\mathrm{C}-\mathrm{O}$ bonds in the PEO side chains at high $\mathrm{NaCl}$ concentrations, leading to a decrease in hydrophilicity of the PEO chains. So, the intermolecular hydrophobic associations are enhanced and large associated aggregates are formed; consequently, the brine solutions present significant elastic character and saltthickening effects. But if the $\mathrm{NaCl}$ concentration is too high, then the aggregates become compact because associations are too strong. Therefore, the sizes of aggregates decrease, and the elastic character becomes weak. This implies that the elastic characters of these solutions are determined by the formation of supra-molecular structures.

PASV and HPAM in aqueous and $70 \mathrm{~g} \mathrm{~L}^{-1} \mathrm{NaCl}$ solutions. Fig. 11 displays the viscoelastic behaviors of $2.0 \mathrm{~g} \mathrm{~L}^{-1}$ PASV and $2.0 \mathrm{~g} \mathrm{~L}^{-1} \mathrm{HPAM}$ in aqueous and $70 \mathrm{~g} \mathrm{~L}^{-1} \mathrm{NaCl}$ solutions. HPAM is a linear water-soluble polymer with super-high molecular weight. Its weight-average molecular weight is $2.2 \times$ $10^{7} \mathrm{~g} \mathrm{~mol}^{-1} \cdot G^{\prime \prime}$ is dramatically lower than $G^{\prime}$, and $\eta^{\prime}$ is obviously lower than $\eta^{*}$ for an aqueous $2.0 \mathrm{~g} \mathrm{~L}^{-1}$ HPAM solution at the angular frequencies of $0.05-50 \mathrm{rad} \mathrm{s}^{-1}$, exhibiting remarkable elastic behavior. However, the HPAM brine solution displays predominantly viscous behavior $\left(G^{\prime \prime} / G^{\prime}>1\right)$ over all angular frequencies. Moreover, $G^{\prime}, G^{\prime \prime}, \eta^{*}$, and $\eta^{\prime}$ values of the aqueous HPAM solution are, respectively, remarkably higher than those of the HPAM brine solution. In contrast, both aqueous and salted $2.0 \mathrm{~g} \mathrm{~L}^{-1}$ PASV solutions exhibit predominantly elastic behavior throughout all angular frequencies, and their $G^{\prime}$ values are dramatically higher than their $G^{\prime \prime}$ values (Fig. 11a). Moreover, $G^{\prime}$ and $\eta^{*}$ of the PASV brine solution are higher than those of the aqueous solution, showing that PASV exhibits more remarkable elastic character in brine solution than in aqueous solution. In addition, for aqueous HPAM and PASV solutions, $G^{\prime \prime}$ of HPAM is higher than $G^{\prime \prime}$ of PASV, but $G^{\prime}$ of HPAM is slightly lower than that of PASV; for salted polymer solutions, both $G^{\prime \prime}$ and $G^{\prime}$ of HPAM is, respectively, obviously lower than those of PASV. As a result, with the addition of a large amount of $\mathrm{NaCl}$, the viscous and elastic characters of HPAM are greatly
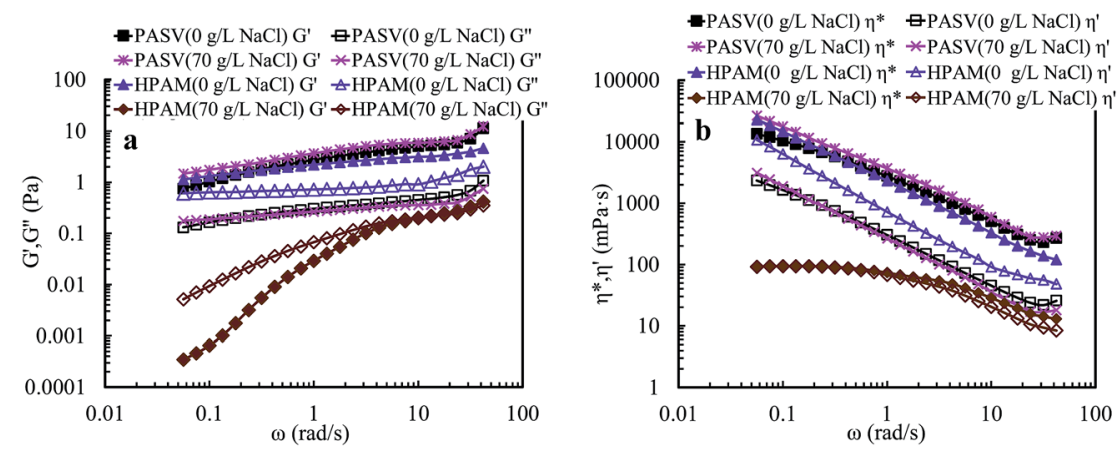

Fig. 11 Influence of angular frequency on elastic modulus $G^{\prime}$ and viscous modulus $G^{\prime \prime}$ (a), and on dynamic viscosity $\eta^{\prime}$ and complex viscosity $\eta^{*}$ (b) for PASV and HPAM in aqueous and $70 \mathrm{~g} \mathrm{~L}^{-1} \mathrm{NaCl}$ solutions. Polymer concentration: $2.0 \mathrm{~g} \mathrm{~L}^{-1}$. 
weakened; on the contrary, the elastic character of PASV is reinforced and its viscous character almost does not change.

Compared with PASV, the molecular weight of HPAM is much higher, but its viscoelastic character is much weaker in solutions with a high $\mathrm{NaCl}$ concentrations. Thus, for PASV and HPAM, their viscoelastic behaviors in aqueous and brine solutions are different, and their mechanisms giving rise to solution behaviors are also different. For the HPAM aqueous and brine solutions, the viscous character is due to the sizes of polymer chains in the solutions, and the elastic character is determined by the formation of aggregating structures. The HPAM chains are expanded and large in aqueous solution. However, in the brine solution, the polymer chains are coiled badly because of very strong charge shielding by $\mathrm{Na}^{+}$ions on $-\mathrm{COO}^{-}$groups, leading to very low $G^{\prime \prime}$ values; the aggregations of polymer chains are seriously destroyed, and so $G^{\prime}$ is abruptly decreased. In contrast, the molecular weight is much lower for PASV, but its polymer chains are rigid because these chains contain branched side chains. So, the PASV chains are expanded in brine solution as well as in aqueous solution; consequently, the $G^{\prime \prime}$ values are high and are almost identical in aqueous and brine solutions. Moreover, for PASV, the associated structures are formed via the intermolecular hydrophobic associations of the octylphenyl groups and the biphenyl groups in aqueous solution, and become larger in $70 \mathrm{~g} \mathrm{~L}^{-1} \mathrm{NaCl}$ because of the complexation of $\mathrm{Na}^{+}$ions with $\mathrm{C}-\mathrm{O}$ bonds in the PEO side chains, and, as a result, the PASV solutions display excellent elastic characters in aqueous and brine solutions.

Effect of SDBS concentration. Fig. 12a and b show, respectively, the effect of SDBS concentration on the viscoelastic moduli and the complex and dynamic viscosities for an aqueous $2.0 \mathrm{~g} \mathrm{~L} \mathrm{~L}^{-1}$ PASV solution. Compared with the aqueous PASV solution, $G^{\prime}$ and $G^{\prime \prime}$ increase remarkably with the addition of 0.2 and $0.5 \mathrm{mmol} \mathrm{L}{ }^{-1} \mathrm{SDBS} ; \eta^{\prime}$ and $\eta^{*}$ also increase. Thus, the two PASV/SDBS solutions predominantly exhibit more obvious elastic behavior. However, as the SDBS concentration is increased to $0.6 \mathrm{mmol} \mathrm{L}^{-1}$, the $G^{\prime}$ and $\eta^{*}$ values of the complex solution are, respectively, lower than those of the PASV solution, and the elastic character of the solution becomes weaker. Finally, by further increasing the SDBS concentration to $1.0 \mathrm{mmol} \mathrm{L}^{-1}$, the $G^{\prime}$ and $G^{\prime \prime}$ values of the complex solution are, respectively, much lower than those of the PASV solution, especially when $G^{\prime} ; G^{\prime}$ is lower than $G^{\prime \prime}$ below $2.0 \mathrm{rad} \mathrm{s}^{-1}$ and $\eta^{*}$ is equal to $\eta^{\prime}$; this solution predominantly exhibits viscous behavior, followed by very weak elastic behavior at higher angular frequencies. For the PASV brine solution with $70 \mathrm{~g} \mathrm{~L}^{-1}$
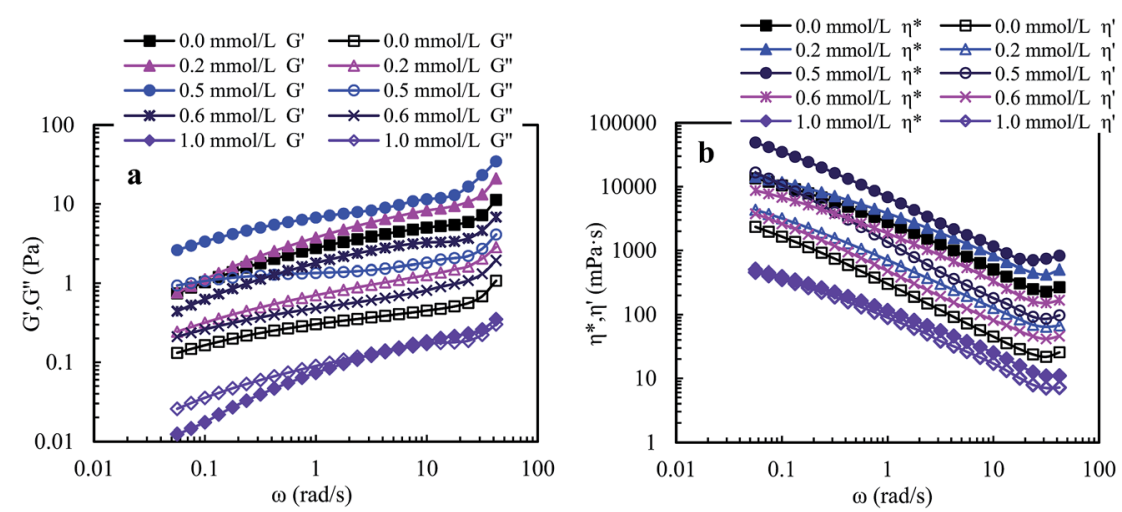

Fig. 12 Influence of angular frequency on elastic modulus $G^{\prime}$ and viscous modulus $G^{\prime \prime}$ (a), and on dynamic viscosity $\eta^{\prime}$ and complex viscosity $\eta^{*}$ (b) for aqueous $2.0 \mathrm{~g} \mathrm{~L}^{-1}$ PASV solutions with different SDBS concentrations.

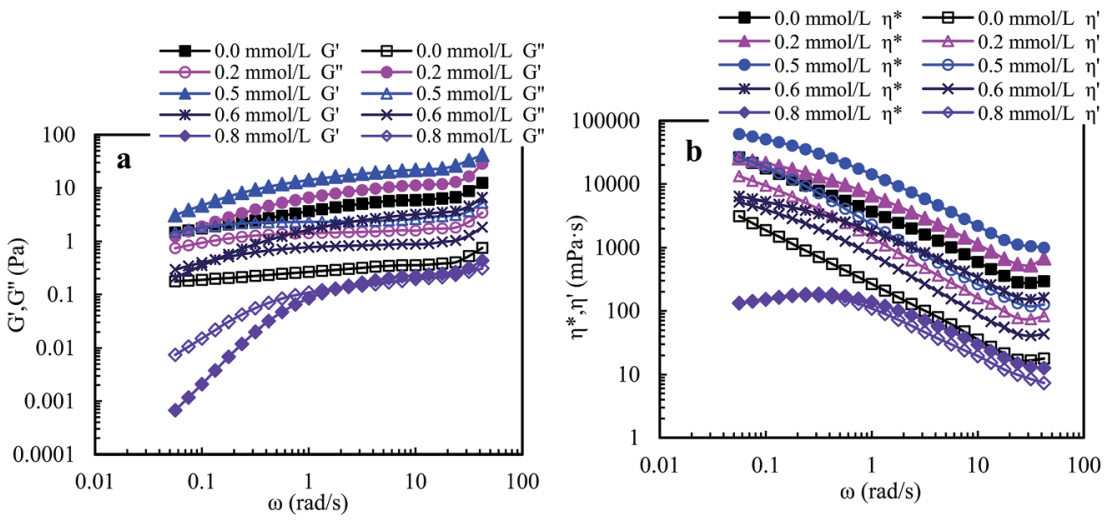

Fig. 13 Influence of angular frequency on elastic modulus $G^{\prime}$ and viscous modulus $G^{\prime \prime}$ (a), and on dynamic viscosity $\eta^{\prime}$ and complex viscosity $\eta^{*}$ (b) of $2.0 \mathrm{~g} \mathrm{~L}^{-1}$ PASV brine solutions with different SDBS concentrations. $\mathrm{NaCl}$ concentration: $70 \mathrm{~g} \mathrm{~L}^{-1}$. 
$\mathrm{NaCl}$, SDBS exhibits a similar effect on the viscoelastic property to that for the aqueous solution (Fig. 13). As the concentration of the added SDBS is obviously lower than its critical micellar concentration (CMC, $1.2 \mathrm{mmol} \mathrm{L}^{-1}$ ), the intermolecular associations are improved and the associated structures become much larger via the physical cross-link of dodecylphenyl groups in SDBS with octylphenyl groups and biphenyl groups from different PASV chains, and so the viscoelastic properties of PASV are enhanced remarkably in water and in brine solutions. However, the associated structures are destroyed because of excessive surfactant in $0.6 \mathrm{mmol} \mathrm{L}^{-1} \mathrm{SDBS}$. Finally, as the SDBS concentration is equal to or higher than CMC of SDBS, no associated structures are formed in PASV solutions and only micelle-like aggregates containing individual octylphenyl groups or biphenyl groups are formed. Thus, the complex viscosity is equal to the dynamic viscosity at low angular frequencies; at high angular frequencies, maybe the PASV chains are expanded, and the PASV solutions present weak elastic behavior.

\section{Conclusions}

A tetra-polymer PASV containing AM, NaAMPS, VP, and a novel macromonomer, allyl-capped octylphenoxy poly(ethylene oxide) with the polymerization degree of 4 (AE), was synthesized. The intermolecular hydrophobic associations of octylphenol and biphenyl groups are not only formed substantially for PASV in water but also reinforced via the complexation of $\mathrm{Na}^{+}$ions with the $\mathrm{C}-\mathrm{O}$ bonds in the PEO side chains for PASV in brine solutions with high salinities. PASV presents an excellent thickening effect induced by salt as well as a good thickening effect in aqueous solutions, and the critical association concentration $\left(C_{\mathrm{p}}^{*}\right)$ is merely $0.7 \mathrm{~g} \mathrm{~L}^{-1}$ in water and is decreased to $0.6 \mathrm{~g} \mathrm{~L}^{-1}$ in $70 \mathrm{~g} \mathrm{~L}^{-1} \mathrm{NaCl}$. Moreover, the apparent viscosities are unconventionally much higher in brine solutions than those in aqueous solutions above $C_{\mathrm{p}}^{*}$. The PASV aqueous and brine solutions display obvious shear thickening behavior at very low shear rate and $30{ }^{\circ} \mathrm{C}$ under atmospheric pressure and exhibit pseudoplastic behavior at high shear rates. It was found that the intermolecular van der Waals interactions of hydrophobic groups were strengthened with an increase in pressure, and the PASV brine solution exhibits surprising pressure-thickening behavior in the range of $0-20 \mathrm{MPa}$ at $65{ }^{\circ} \mathrm{C}$. Additionally, during repetitious shear cycles, the appropriate shear is beneficial for stretching PASV polymer chains and forming associated structures, and the intermolecular associations are reversible. These fluid behaviors of PASV solutions conform to the requirement for oil-flooding polymer solutions in oil reservoirs.

For PASV in water and in $70 \mathrm{~g} \mathrm{~L}^{-1} \mathrm{NaCl}$, the outstanding elastic characters are exhibited above a polymer concentration of $1.0 \mathrm{~g} \mathrm{~L} \mathrm{~L}^{-1}$. Moreover, the PASV brine solutions display surprisingly more obvious elastic character than the aqueous PASV solutions in the range of $0.05-50 \mathrm{rad} \mathrm{s}^{-1}$ when the polymer concentrations are higher than $1.0 \mathrm{~g} \mathrm{~L}^{-1}$. The $2.0 \mathrm{~g} \mathrm{~L}^{-1}$ PASV brine solutions exhibit predominantly excellent elastic behavior over all angular frequencies at high $\mathrm{NaCl}$ concentrations of 70-110 $\mathrm{g} \mathrm{L}^{-1}$, especially in $70 \mathrm{~g} \mathrm{~L}^{-1} \mathrm{NaCl}$. This is significantly different from linear associating polymers without a macromonomer. The predominant elastic behaviors of PASV aqueous and brine solutions are due to the formation of large associated structures in water and the obvious enhancement of intermolecular hydrophobic associations induced by salt. Moreover, the viscous and elastic characters are enhanced remarkably with the addition of a suitable SDBS amount for PASV aqueous and brine solutions. PASV should be expected to be applied in oil reservoirs with high salinities.

\section{Conflicts of interest}

The authors declare no competing financial interest.

\section{Acknowledgements}

We acknowledge the financial support of National Natural Science Foundation of China (Contract Grant No.: 51674045), Sichuan Support Foundation for Academic and Technological Leader (Contract Grant No.: XDPY-1702), and Sichuan Science and Technology Support Project (Contract Grant No.: 2015SZ0007).

\section{References}

1 C. L. Li, Mechanism of Reservoir Engineering, Petroleum Industry Press, Beijing, 2011.

2 J. J. Sheng, Modern Chemical Enhance Oil Recovery, Elsevier Ltd, New York, 2011.

3 K. C. Tam and C. Tiu, Colloid Polym. Sci., 1990, 268, 911-920.

4 R. S. Seright, A. R. Campbell, P. S. Mozley and P. Han, SPE J., 2010, 15, 341-348.

5 A. R. Al Hashmi, R. S. Al Maamari, I. S. Al Shabibi, A. M. Mansoor, et al., J. Pet. Sci. Eng., 2013, 105, 100-106.

6 J. C. Jung, K. Zhang, B. H. Chon and H. J. Choi, J. Appl. Polym. Sci., 2013, 127, 4833-4839.

7 A. Samanta, A. Bera, K. Ojha and A. Mandal, J. Chem. Eng. Data, 2010, 55, 4315-4322.

8 C. L. McCormick and C. Salazar, J. Macromol. Sci., Part A: Pure Appl. Chem., 1992, 29, 193-205.

9 M. Rashidi, A. M. Blokhus and A. Skauge, J. Appl. Polym. Sci., 2010, 117, 1551-1557.

10 M. Rashidi, A. M. Blokhus and A. Skauge, J. Appl. Polym. Sci., 2011, 119, 3623-3629.

11 R. J. English, J. H. Laurer, R. J. Spontak and S. A. Khan, Ind. Eng. Chem. Res., 2002, 41, 6425-6435.

12 R. G. Ezell and C. L. McCormick, J. Appl. Polym. Sci., 2007, 104, 2812-2821.

13 G. L. Smith and C. L. McCormick, Macromolecules, 2001, 34, 5579-5586.

14 J. T. Ma, R. H. Huang, L. Zhao and X. Zhang, J. Appl. Polym. Sci., 2005, 97, 316-321.

15 L. Ye, L. J. Mao and R. H. Huang, J. Appl. Polym. Sci., 2001, 82, 3552-3557.

16 N. J. Lai, Z. B. Ye, J. Dong, X. P. Qin, et al., J. Appl. Polym. Sci., 2013, 129, 1888-1896. 
17 S. H. Gou, Q. Zhang, C. Yang, Q. Li, et al., RSC Adv., 2016, 6, 76696-76706.

18 N. J. Lai, Y. Zhang, Q. Zhou, Z. B. Ye, et al., Energy Fuels, 2016, 30, 9362-9371.

19 D. L. Li, W. S. Zha, S. F. Liu, et al., J. Pet. Sci. Eng., 2016, 147, 308-316.

20 H. T. Li, Y. Li, S. N. Chen, et al., Energy Fuels, 2016, 30, 70827093.
21 J. Wang, H. Q. Liu and J. Xu, J. Dispersion Sci. Technol., 2013, 34, 417-426.

22 H. Jiang, W. Wu, D. Wang and Y. Zeng, et al., SPE, 2008, DOI: 10.2118/115315-MS.

23 H. Xia, D. Wang, J. Wu and F. Kong, $S P E$, 2004, DOI: 10.2118/ 88456-MS.

24 A. S. Kimerling, W. E. Rochefort and S. R. Bhatia, Ind. Eng. Chem. Res., 2006, 45, 6885-6889. 